\title{
KANTİTATİF MİKROBİYOLOJİK ANALİZLERDE ÖLÇÜM BELİRSİZLİĞİ HESAPLANMASINDA FARKLI YAKLAŞIMLARIN KARŞILAŞTIRILMASI
}

\author{
Nuray Gamze Yörük ${ }^{*}$ \\ Kocaeli Gıda Kontrol Laboratuvar Müdürlüğü, Mikrobiyoloji Birimi, Kocaeli, Türkiye
}

Geliş / Received: 06.02.2021; Kabul / Accepted: 24.04.2021; Online bask1 / Published online: 05.05.2021

Yörük, N. G. (2021). Kantitatif mikrobiyolojik analizlerde ölçüm belirsizliği hesaplanmasında farklı yaklaşımların karşılaştırılması. GIDA (2021) 46 (3) 707-725 doi: 10.15237/gida. GD21033.

Yörük, N. G. (2021). Comparison of various approaches in calculation of measurement uncertainty in quantitative microbiological analysis. GIDA (2021) 46 (3) 707-725 doi: 10.15237/gida. GD21033.

\section{ÖZ}

TS EN ISO/IEC 17025:2017 standardı ile akreditasyon kapsamındaki laboratuvarlar, sonuçlarının güvenilirliğini ortaya koyabilmek için analiz süresince ölçüm sonucuna yansıma etkisi bulunan tüm değişkenlerin (matriks, donanım, vb) dağılımlarını karakterize ederek, ölçümün sonucuyla bağlantılı olan parametreler olarak tanımlanan kantitatif analizlerinde akreditasyonun bir parçası olan ölçüm belirsizliği hesaplamalarını değişik metotlarla gerçekleştirmektedirler. Araştırma, ölçüm sonuçlarına etki ederek değișikliklere neden olan tüm değişkenlerin kullanılmasıyla ortaya çıkan ölçüm belirsizliklerinin farklı yöntemlerle hesaplanmasını içermektedir. Bu çalışmada, sütlerde ISO 4833-1 standardına göre toplam mezofilik aerobik mikroorganizma, yemeklerde ISO 7932 metodu ile Bacillus cereus, peynirlerde ise ISO 16649-2 standardı ile Escherichia coli analizleri çalısıllmıştır. Tüm veriler, International Organization of Standardization (ISO) standard, NordVal International (NMKL) No.8 yöntemi ve EuroLab Teknik Prosedürüne (EuroLab) göre $\log _{10}$ tabanına çevrilerek istatistiki olarak değerlendirilmiştir. ISO/TS 19036 metoduna ait belirsizliklerin EuroLab Teknik Prosedürüne göre anlamlı $(P<0.05)$ ISO/TS 19036 standardı ve EuroLab Teknik Prosedürünün ise NMKL No.8 yöntemine göre daha hassas belirsizlik verdikleri ortaya konulmuştur.

Anahtar kelimeler: Mikrobiyolojik analiz, ölçüm belirsizliği, ISO 19036, EuroLab teknik prosedürü, NMKL No. 8

\section{COMPARISON OF VARIOUS APPROACHES IN CALCULATION OF MEASUREMENT UNCERTAINTY IN QUANTITATIVE MICROBIOLOGICAL ANALYSIS}

\begin{abstract}
Laboratories accredited with TS EN ISO/IEC 17025:2017 standard characterize distribution of all variables (matrix, hardware, etc.) that have reflection effects on measurement results throughout analysis and use different methods to conduct measurement uncertainty calculations as a part of accreditation in quantitative analysis defined as parameters linked to measurement result. The study involves calculation using various methods of measurement uncertainties that emerge from using all variables that cause changes by effecting measurement results. In this study, total mesophilic aerobic microorganisms were studied in milk according to ISO 4833-1 standards, ISO 7932 method was used
\end{abstract}

\footnotetext{
${ }^{*}$ Yazışmalardan sorumlu yazar / Corresponding author

17: nuraygamzeyoruk@gmail.com

(ग): (+90) 5053505425

且: (+90) 2623121065
}

Nuray Gamze Yörük; ORCID no; 0000-0003-0867-4141 
in food to study Bacillus cereus, while in cheese ISO 16649-2 standard was used to study Escherichia coli analysis. All data were converted to base $\log _{10}$ and statistically assessed using International Organization of Standardization (ISO) standard, NordVal International (NMKL) No.8 method and EuroLab Technical Procedure. It was established that uncertainties under ISO/TS 19036 method were creating more significant uncertainties $(P<0.05)$ while ISO/TS 19036 standard and EuroLab Technical Procedure were resulting in more sensitive uncertainties compared to NMKL No.8 method.

Keywords: Microbiological analysis, measurement uncertainty, ISO 19036, EuroLab Technical Procedure, NMKL No. 8

\section{GİRİ̧̧}

Evrensel düzende gıda canlılar için temel bir ihtiyaç olmakla beraber zamanla sağlık açısından bir tehdit unsuru da olmaya başlamıştır. Bu durum ne yazık ki günümüze kadar artan düzeylerde çeşitli fiziksel, kimyasal ve biyolojik etmenler nedeni ile meydana gelmiş, artan popülasyonla beraber teknoloji çağının getirdiği yeniliklerin olumlu yönde kullanılmaması bu tür risk unsurlarının artışına kimi zaman olumsuz yönde katkıda bulunmuştur. Gıda güvenliği ve halk sağlığı bir bütün olarak ele alındığında, canlıların vazgeçilemez temel yaşam kaynağı olan gidalarda denetim ve analiz ilişkisine dayalı kontrol mekanizmalarının daha să̆lam, güvenilir ve doğru işletilmesinin gerekliliğinin önemi ortaya çıkmaktadır. Özellikle gidalarda mikrobiyolojik analizleri gerçekleştiren laboratuvarların ise tüm analizlerinde akreditasyon kriterleri doğrultusunda yöntemlerini belirleyerek ulusal ve uluslararası platformlarda analiz sonuçlarını geçerli kıldıklarını göstermelerinin gerekliliği her geçen gün daha da artmaktadır. Çünkü, gıda kaynaklı enfeksiyon ve/veya intoksikasyonların temelinde mikrobiyel etkenler rol oynamaktadır. $\mathrm{Bu}$ sebeple gida analizlerinin ulusal ve/veya uluslararası standartlar1 esas alınarak gerçekleştirilmesi gerek halk sağlığ gerek ürün güvenliği noktalarında fayda sağlayacak, uluslararası boyutta gerçekleştirilmesi planlanan ticari anlaşmalara bile olumlu etkileri zamanla daha fazla yansiyacaktır. Gida analizlerini TS EN ISO/IEC 17025: 2017 "Deney ve Kalibrasyon Laboratuvarlarının Yetkinliği için Genel Gereklilikler" standardı ile gerçekleştiren akredite laboratuvarlar standardın tüm gerekliliklerini yerine getirmek durumundadırlar. Diğer bir deyişle, bu standardın 7.2 Metotların Seçilmesi, Doğrulanması ve Geçerli Kılınması maddesinde, laboratuvarın analizleri için kullandığı metotlarını uygun bir şekilde geçerli kıldığını veya doğruladığını göstermesinin laboratuvarlar tarafindan sağlanması gereken bir akreditasyon şartı olduğu bildirilmektedir. Ayrıca, bir ölçümün kalitesinin, laboratuvar tarafindan analize ilişskin metodun geçerli kılınması/doğrulanması, ölçüm belirsizliğinin tahmini, izlenebilirliğin sağlanması ile ortaya konulmasının gerekliliği ve kalite kontrol çalışmaları ile devamlılığının sağlanması gerektiği de belirtilmiştir (TÜRKAK, 2019). ISO 17025 standardına göre bir metodun geçerli kılınması, belirlenen gerekliliklerin amaçlanan kullanım için yeterli olduğu durumlarda yapilan doğrulama olarak tanımlanırken; doğrulamanın ise belirli bir ögenin belirlenmiş gereklilikleri karşıladığına dair nesnel kanıt sağlaması şeklinde ifade edilmektedir (ISO, 2017; TÜRKAK, 2019). Laboratuvar analiz sonuçlarının geçerli kılınması için öncelikle ölçüm doğruluğunu yani elde ettiği sonuç ile gerçek değer arasındaki ilişkiyi ortaya koymalıdır (Forster, 2003; ISO, 2017a, TÜRKAK, 2019). Bu şekilde ölçümlerin doğruluğu hesaplanırken, doğruluğun 2 unsuru olan gerçeklik ve kesinlik göz önünde bulundurulurken; kesinlikte ise tekrarlanabilirlik $\left(\mathrm{s}_{\mathrm{r}}\right)$, ara kesinlik ve tekrarüretilebilirlik $\left(\mathrm{S}_{\mathrm{R}}\right)$ sonuçlar1 hesaba katılmaktadır (ISO, 2017b; TÜRKAK, 2019; Y1lmaz vd., 2019; ISO, 2021). Bunun bir faydası ölçüm belirsizliğine etki eden tüm risklerin ortaya konulmasıdır (Dereani ve Sarić, 2010).

G1da analizlerini TS EN ISO/IEC 17025: 2017 "Deney ve Kalibrasyon Laboratuvarlarının Yetkinliği için Genel Gereklilikler" standardı ile gerçekleştiren akredite laboratuvarlar standardın tüm gerekliliklerini yerine getirmek durumundadırlar. Diğer bir deyişle, bu standardın 7.2 Metotların Seçilmesi, Doğrulanması ve Geçerli Kılınması maddesinde, laboratuvarın analizleri için kullandığı metotlarını uygun bir 
şekilde geçerli kıldığını veya doğruladığını göstermesinin laboratuvarlar tarafindan sağlanması gereken bir akreditasyon şartı olduğu bildirilmektedir. Ayrıca, bir ölçümün kalitesinin, laboratuvar tarafindan analize ilişkin metodun geçerli kıllınması/doğrulanması, ölçüm belirsizliğinin tahmini, izlenebilirliğin sağlanması ile ortaya konulmasının gerekliliği ve kalite kontrol çalışmaları ile devamlılı̆̆ının sağlanması gerektiği de belirtilmiştir (TÜRKAK, 2019).

ISO 17025 standardına göre bir metodun geçerli kılınması, belirlenen gerekliliklerin amaçlanan kullanım için yeterli olduğu durumlarda yapılan doğrulama olarak tanımlanırken; doğrulamanın ise belirli bir ögenin belirlenmiş gereklilikleri karşıladığına dair nesnel kanıt sağlaması şeklinde ifade edilmektedir (ISO, 2017; TÜRKAK, 2019). Laboratuvar analiz sonuçlarının geçerli kılınması için öncelikle ölçüm doğruluğunu yani elde ettiği sonuç ile gerçek değer arasındaki ilişkiyi ortaya koymalıdır (Forster, 2003; ISO, 2017a, TÜRKAK, 2019). Bu şekilde ölçümlerin doğruluğu hesaplanırken, doğruluğun 2 unsuru olan gerçeklik ve kesinlik göz önünde bulundurulurken; kesinlikte ise tekrarlanabilirlik $\left(\mathrm{s}_{\mathrm{r}}\right)$, ara kesinlik ve tekrarüretilebilirlik $\left(\mathrm{S}_{\mathrm{R}}\right)$ sonuçları hesaba katılmaktadır (ISO, 2017b; TÜRKAK, 2019; Y1lmaz vd., 2019; ISO, 2021). Bunun bir faydası ölçüm belirsizliğine etki eden tüm risklerin ortaya konulmasıdır (Dereani ve Sarić, 2010).
Metot geçerli kılma çalışmalarında uygulanan ölçüm belirsizliği hesaplamalarında ideal olarak ayn1 laboratuvarda, ayn numune ve metot ile farklı zamanlarda farklı analistler, farklı donanım vb. kullanılarak elde edilen orta/ara kesinlik veya laboratuvar içi uyarlık olarak tanımlanan standart sapma değeri kesinlik verisi olarak kullanılmaktadır (TÜRKAK, 2015). Kantitatif mikrobiyolojik analizlerde kesinliğin ve gerçekliğin doğrulanması gerekmektedir. Kesinliğin doğrulanması sırasında Ölçüm Belirsizliği de hesaplanmaktadır. Bu sırada ölçümün belirsizliğine katk1 sağlayan çeşitli kaynaklarda bulunmaktadır (Forster, 2003; ISO, 2019; Y1lmaz vd., 2019; ISO, 2021). Bu kaynaklar;

Teknik belirsizlik; operasyonel değişiklikler, dilüsyon, tekrarüretilebilirlik kaynaklı sapmalar,

-Matriks belirsizliği; matriks çeşidi ve içinde homojen karışımı sağlanamamış mikroorganizma çalışmalarından düşük seviyeli tekrarüretilebilirlik verilerinin elde edilmesi, vb.

-İstatistiksel dağılım belirsizliği; test organizmasının sayımı ve doğrulanmasında koloni sayımı için poisson dağılımı ya da doğrulama belirsizliğinin kullanımı; en muhtemel sayım yöntemi için en muhtemel sayım yöntemi belirsizliğidir (EuroLab, 2007; ISO, 2019).

Belirsizlik hesabı ile ilgili iki ayrı yaklaşım bulunmaktadır;

-Global Yaklaşım $=$ Top down $=$ Kara kutu $=$ Yukarıdan aşağıya ilerleme $=$ Tüme varım

-Bileşen Yaklaşımı = Bottum up $=$ Adım adım $=$ Aşağıdan yukarı ilerleme $=$ Tümden gelim

Çizelge 1. Global yaklaşım ile bileşen yaklaşımının optimum kullanım alanları

(NMKL, 2017; ISO, 2019)

Table 1. Optimum Uses Area of Component Approach with Global Approach (NMKL, 2017; ISO, 2019)

\begin{tabular}{|l|l|}
\hline $\begin{array}{l}\text { Global Yaklaşım } \\
\text { (Global Approach) }\end{array}$ & $\begin{array}{l}\text { Bileşen Yaklaşımı } \\
\text { (Component Approach) }\end{array}$ \\
\hline $\begin{array}{l}\text { Operasyonel varyansın dağılım varyansından büyük } \\
\text { olması beklenen katı örneklerde }\end{array}$ & Düşük mikroorganizma yükü var ise \\
\hline Çalısılan örneklerde hetorojenlik fazla ise & \\
\hline Laboratuvarlar arası karşılaştırma yapılacak ise & \\
\hline
\end{tabular}


Ölçüm belirsizliği, yapılan ölçümün hangi değerler arasında yer alacağını, güven aralığını anlatmaktadır. Belirsizlik ölçüm sonuçlarının dağılımını göstermekle beraber tam olarak ortadan kaldırılamaz. Ancak, hiçbir zamanda tam olarak hesaplanamaz. Tek başına bir analiz değildir (Corry, 2007). \%95 güven aralığında tahminidir ve ancak belirsizliğe etki eden faktörlerin iyileştirilmesi ile küçültülebilir ve $\% 99$ olarak bile güven aralığı sağlanabilir. Belirsizliğin hesaplanmasında tekrarüretilebilirlik verilerinin kullanılması dolayısı ile tekrarüretilebilirliği etkileyen faktörler olan;

-Zaman (Z): Birbirini izleyen ölçmeler arasındaki zaman aralığı kısa veya uzun olmalıdır.

-Kalibrasyon (K): Birbirini izleyen ölçmelerin gruplar arasında farklı donanım ile kalibre edilmeden önce ve sonraki şeklinde kullanımıdır.

-Deneyi yapan kişi $(\mathrm{O})$ : Birbirini izleyen ölçmelerin fark1 deneyi yapan kişiler tarafindan gerçekleştirilmesidir.

-Donanım (D): Ölçmelerde farklı donanımın kullanılmasıdır (TS, 2000; Lombard, 2006; ISO, 2021).

Ölçüm sonuçları referans materyal, yeterlilik testleri, ilgili analize ilişkin standart, numunenin homojen dağllımı, referans kültürün homojen dağglımı, tek suş ya da çokça mikroorganizma bulunan ortamlarda hedef mikroorganizmanin baskılanması, mikrobiyel gelişim ya da ölme, analist etkisi, gerçek koloni sayımı, donanımın kalibrasyon durumu, istatistiksel dağılım gibi tüm bu faktörlerle etkilenir (NMKL, 2004; Gašljević, 2004).

ISO 17025 standardına göre bazı durumlarda deney metodunun kendisinden kaynaklı ölçüm belirsizliği dikkatli, metrolojik ve istatistiksel olarak hesaplanamamakta işte bu şekilde deney yönteminin ölçüm belirsizliğinin kesin olarak değerlendirmesinin mümkün olmadığ durumlar içinse ya analizle ilgili tüm belirsizlik bileşenleri ayr1 ayr1 ortaya konulmalı ya da yöntemin uygulanmasina yönelik uygun bir tahminde bulunulması önerilmektedir (TÜRKAK, 2015; ISO, 2017a; VIM, 2008). Bu anlamda akreditasyonun İyi Laboratuvar Uygulamalarına yardımcı olarak çeşitli belirsizlik kaynaklarını minimize etmeye yarayan bir sistem olduğu ortaya çıkmaktadır (Jarvis vd., 2007).

$\mathrm{Bu}$ çalışmanın amacı, gıda zehirlenmelerinin temelinde çoğunlukla risk teşkil eden mikrobiyel kaynaklı etmenlere yönelik gerçekleştirilen ISO 7932 metodu ile yemeklerde B. cereus, ISO 166492 metodu ile peynirlerde E. coli ve ISO 4833-1 metodu ile sütlerde toplam mezofilik aerobik mikroorganizmaların mikrobiyolojik analizlerde kesinliği sağlamak üzere yapılan çalışmalardan biri olan tekrarüretilebilirlik çalışmalarının doğruluğu kabul edilmiş çeşitli uluslararası metot ve yaklaşımlarla ölçüm belirsizliği sonuçlarının karşılaştırmalı olarak ortaya konulmasıdır. Elde edilen ölçüm belirsizliği verileri ile bu tarz çalışmalarda hangi metotla hangi aralıkta çalışılabileceği ve ilgili metodun ne kadar hassasiyetle istatistiki sonuçlar verdiği irdelenmiştir.

\section{MATERYAL VE YÖNTEM}

Araştırmada, tekrarlanabilirlik çalışmaları ardından her analize ait ölçüm belirsizliklerinin ortaya konulabilmesi için yapilan tekrarüretilebilirlik çalışmalarında sahada sıklıkla ilgili numunelerde herhangi bir kontamine durum söz konusu olduğunda ya da yeterli isıl işlem uygulamalar1 ve hijyen kriterlerine dikkat edilmediğinde enfeksiyon ya da intoksikasyona neden olan ayrica heterojenlikleri ile elde edilebilecek en büyük ölçüm belirsizlikleri ile karşılaştırma yapılması bakımından 3 ayrı gıda matriksi ile (yemek, peynir ve süt) 3 farklı analiz metodu kullanilarak (ISO 7932 metodu ile B. cereus, ISO 16649-2 metodu ile E. colive ISO 48331 metodu ile toplam mezofilik aerobik mikroorganizma) paralel olarak, 4 farklı analist tarafindan 10 ayrı günde ve tüm şartlar değiştirilerek (matriks, etüv, pipet, terazi, besiyeri, dilüsyon, hacim, vb donanımlar) çalışmalar gerçekleştirilmiştir.

Araştırmada, B. cereus ile çalışma yapılabilmesi için yemek numuneleri NCTC 7464, B. cereus suşu ile toplam mezofilik aerobik mikroorganizma çalışmalarında sütler NCTC 10400 Bacillus subtillis subsp. spizizenii sușu ile, E. coli çalıșmalarında peynir numuneleri NCTC 10788 E. coli suşu ile 
kirletme yapılarak gerçekleştirilmiştir. Tüm analizlerin gerçekleştirilmesi için aseptik ortam koşullarında ve otoklavlanarak steril hale getirilmiş $10 \mathrm{~g} / \mathrm{mL}$ olarak tartımı yapılan tüm numunelere $90 \mathrm{~mL}$ tamponlanmış peptonlu su (Liofilchem ${ }^{\circledR}$ REF 499030, ITALY) ilave edilerek, değişen dilüsyonlarda spike işlemi gerçekleştirilmiş (mikroorganizma yükleri önceden belirlenmiş) ve toplam mezofilik aerobik mikroorganizması ile kontamine süt numuneleri ile $B$. cereus ile kontamine yemek numuneleri $30^{\circ} \mathrm{C}^{\prime}$ de 24 saat, E. coli ile kontamine peynir numuneleri ise $37^{\circ} \mathrm{C}$ 'de 24 saat inkübe edilmiştir. İnkübasyon sonrasında, E. coli sayım analizleri için TBX agara (LAB M- Neogen Culture Media NCM1001A Harlequin TBGA, UK) dökme metoduna göre, B. cereus sayımı için Bacillus cereus mediuma (LAB M Neogen Culture Media LAB073, UK) yayma metoduna göre, toplam mezofilik aerobik mikroorganizma sayımı için Plate Count agara (LAB M- Neogen Culture Media NCM0010A, UK) dökme metoduna göre ekimler yapilarak sirayla, $41,5^{\circ} \mathrm{C}^{\prime}$ de 24 saat, $30^{\circ} \mathrm{C}$ 'de 48 saat, $30^{\circ} \mathrm{C}$ 'de 72 saat inkübe edilerek, sayımlar yapılmıştır.

Elde edilen tüm sonuçlar $\log _{10}$ tabanına çevrilerek ve 1 . analist 2 . analistle, 1 . analist 3 . analistle, 1. analist 4. analistle, 2 . analist 3. analistle, 2. analist 4. analistle ve 3. analist 4. analistle karşılaştırılarak ISO/TS 19036, NMKL No.8 standartlar1 ve EuroLab teknik prosedürü (EuroLab, 2007; Torlak, 2012) ile değerlendirilerek, 3 ölçüm belirsizliği yaklaşımı arasındaki hassasiyet fark1 istatistiksel olarak ortaya konulmuştur.

\section{ISO 19036 Metodu ile Ölçüm Belirsizliği Analizi}

Analistler için değişken olarak oluşturulan A ve B koşulları bulunur. A koşulunda kullanılan tüm faktörlerin B koşulunda kullanılmadığı yine B koşulundaki tüm faktörlerin ise A koşulunda kullanılmadığı ortamlarda gerçekleştirilen analizler, (örn; farklı parti besiyerinin kullanımı, test porsiyonlarına farklı suşların inokülasyonu, farklı inkübatörlerde inkübasyonun yapılması, farklı otomatik pipet kullanımı ve farklı hacim ölçerler gibi analizin her basamağında olası muhtemel değişkenliklerin sağlanması, vb).ile analistlerin sonuçları $a_{i}$ ve $b_{i}$ olarak ele alınmıştır (ISO, 2019; Y1lmaz vd., 2019; ISO, 2021).

a: Farklı koşullarda ortaya çıan analist sonucu

$b_{i:}$ Farklı koşullarda ortaya çıkan diğer analistin sonucu

n: çalışmadaki tekrar sayısı

$\mathrm{S}_{\mathrm{R}}$ : tekrarüretilebilirlik standart sapmas

$\mathrm{S}_{\mathrm{IR}}$ : laboratuvariçi tekrarüretilebilirlik standart sapmas1

$S_{\mathrm{I} R}=\sqrt{\frac{\sum_{i=1}^{n}\left(a_{i}-b_{i}\right)^{2}}{2 n}}$

Tekrarüretilebilirlik çalışmalarından elde edilen standart sapmanin (s), tüm ölçümlerin ortalamasına ( $\dot{\mathrm{x}})$ oranı bağıl standart sapmayı verir (RSD- RSD ). RSD formülizasyonu (2) ile gösterilmiştir.

$R S D=\frac{S \tan \operatorname{dartSapma}(s)}{\operatorname{Ortalama}(x)} R S D_{R}=\frac{S}{\bar{X}}$

Birleştirilmiş tekrarüretilebilirlik relatif standart sapmas1 (RSD $\mathrm{RC}_{\text {) }}$ ise toplam bağ1l standart sapmanın $n$ çalışma tekrar sayısına bölümünün karekökünü ifade etmektedir.

$R S D_{R C}=\sqrt{\frac{\sum R S D_{R}^{2}}{n}}$

$\mathrm{RSD}_{\mathrm{RC}}$ : birleştirilmiş tekrarüretilebilirlik relatif standart sapmasi

¿RSD: toplam bağıl standart sapma

\section{NMKL No.8 Standardı ile Ölçüm Belirsizliği} Analizi

NMKL No.32'nin atıfta bulunarak temel aldığ1 NMKL No.8 standardı tekrarüretilebilirlik ve ölçüm belirsizliği hesaplamalarını içerir. Değişkenler aynı ISO 19036 standardında belirtildiği gibidir. NMKL No. 8 standardına göre tekrarüretilebilirlik verileri tekrarlanabilirlik verilerinden de elde edilebilir (NMKL, 2004; Yilmaz vd., 2019).

İlk olarak Toplam Standart sapma hesaplanır: 
$S_{r}=\sqrt{\frac{\sum_{i=1}^{n}\left(x_{i}-\bar{x}\right)^{2}}{n-1}}$

$\mathrm{S}_{\mathrm{r}::}$ Standart Sapma

$\bar{x}$ : Sonuçların ortalaması

n: Çalışılmış olan tekrar sayısı

$\mathrm{x}_{\mathrm{i}}$ : Her bir analistin sonucu

Verilerin ortalamaları alınır,

$\bar{x}=\frac{\sum_{i=1}^{n} x_{i}}{n}$

Standart sapmaların ortalaması alınır,

$S_{r}=\sqrt{\frac{S r_{1}{ }^{2}+S r_{2}{ }^{2}+S r_{3}{ }^{2}+S r_{4}{ }^{2}}{4}}$

Ortalamaların standart sapması hesaplanır,

$S_{x}=\sqrt{\frac{\sum_{i=1}\left(x_{i}-\mathrm{y}^{2}\right)}{n-1}}$

$\mathrm{x}_{\mathrm{i}}$ : Her bir analistin sonucu

y: 2 analistin tüm sonuçlarının $(\log 10)$ ortalaması

Gruplar arası varyans $\mathrm{S}_{\mathrm{L}}^{2}$ hesaplanır;

$S_{L}^{2}=S_{x}^{2}-\frac{S_{r}^{2}}{n}$

Standart belirsizlik hesaplanır;

$u=S_{R}=\sqrt{S_{r}{ }^{2}+S_{L}{ }^{2}}$

$\mathrm{S}_{\mathrm{R}:}$ Standart belirsizlik

$U=2 S_{R}$

\section{U: Genişletilmiş ölçüm belirsizliği}

\section{EuroLab Teknik Prosedürü ile Ölçüm Belirsizliği Analizi}

Çalıșmalarda ISO 19036 ve NMKL No. 8 standartlar1 ile beraber Eurolab Teknik Prosedürü No.1 (2007) bölüm 3.1. Verifikasyonlarda Ölçüm Belirsizliği ile hesaplamalar dahilinde de çalışmalar paralel olarak gerçekleştirilmiştir. Koloni sayımı tekniğinde, petrideki koloni sayısı azaldıkça ve genel tasarım düşük sayımlar için uygun olmadığından, öngörülemeyen varyasyon hızla artmaktadır. Bu teknik prosedüre göre petride koloni sayısı 10'dan az olan sayım sonuçlarinın hesaplamalardan çıkarılması gerekmektedir (EuroLab, 2007; Torlak, 2012). Gerek çalışmada 10'dan küçük koloni elde edilememesi (yükleri belli dilüsyondaki numuneler) gerekse istatistiksel metot hesaplamalarında standart ya da metotlara eşit koşullarda davranılması gerektiğinden araştırmada elde edilen sonuçların tümü $\log _{10}$ 'a çevrilmiştir. Laboratuvar içi tekrarüretilebilirlik standart sapma hesabi ve tanımlamalar formüllerle beraber verilmiştir.

$\operatorname{RSDR}_{W=\frac{\overline{\mathrm{R}}}{\mathrm{d} 2}}$

RSD: bağ1l standart sapma

R: ortalama bağıl değer aralığını verir.

d2: dönüşüm faktörünü verir. Paralel sayımlar için d2 faktörü kullanılır. d2= 1.128 olarak alınır.

$R=\frac{\sum R i}{n}$

n kadar sayıda paralel sayım için.

$\mathrm{R}_{\mathrm{i}:}$ Gerçek bağıl değeri verir.

$$
R_{i=\frac{A_{i}-B_{i}}{m_{i}}}
$$

$\mathrm{A}_{\mathrm{I}}, \mathrm{B}_{\mathrm{I}}: 2$ analistin verileri

$\mathrm{m}_{\mathrm{i}}: 2$ analistin sonuçlarının aritmetik ortalaması

$U=k * u$

k: \% 95 güven aralığ1 kapsama faktörü 2

u: RSDR ${ }_{W}$ hesabindan gelen belirsizlik

\section{İstatistiksel Analizler}

Analiz sonuçlarının değerlendirilmesi amacıyla ilk olarak tüm sonuçlar 3 farklı metoda ait formüllerle Excel üzerinde hesaplanmıștır. Elde edilen verilerin analizi SPSS 24.0 ile yapılmıştır. Çalışmada 4 farklı değerlendiricinin önce 2 farklı formül ile $\mathrm{Sr}$ ve $\mathrm{U}$ değerleri hesaplanmış ve aralarındaki uyum gösterme durumunun incelenmesi için Kendall's tau b Katsayısı ve Spearman's rho Katsayısı hesaplanmıştır. Bununla 
birlikte 3 değişik metot birbirleri ile karşılaştırılmış olup Çizelge 2 ve Çizelge 3' de gösterilmiştir. ISO 19036 standardı ile EuroLab Teknik Prosedürü ölçüm sonuçlarının birbirine yakınlığının karşılaştırılması amacıyla bağımlı gruplar $T$ testi yapılmışıtır.

\section{BULGULAR VE TARTIŞMA}

Çalışma sonuçlarımız ISO 19036, NMKL No.8 ve EuroLab Teknik Prosedürüne göre istatistiksel olarak değerlendirilmişlerdir. ISO 19036 metodu ile EuroLab Teknik Prosedürü ölçümlerinin karşılaştırılması amacıyla yapılan bağımlı gruplar $t$ testi sonuçları Çizelge 2'de verilmiştir. ISO 19036, NMKL No.8 ve EuroLab Teknik Prosedürüne ait $S_{R}$ ve U değerlerinin karşılaşturılması ise Çizelge 3' de gösterilmiştir. ISO 19036 ve EuroLab Teknik Prosedürü değerleri arasındaki yakınlık karşılaştırması ise Şekil 1, Şekil 2, Şekil 3, Şekil 4, Şekil 5 ve Şekil 6 ve Şekil 7' deki Regresyon grafikleri ile ortaya konulmuştur. ISO 19036, EuroLab Teknik Prosedürü ve NMKL No.8'e ait Ölçüm Belirsizliği Karşılaştırmalarına ait farkliliklar ise Çizelge 4, Çizelge 5, Çizelge 6, Çizelge 7, Çizelge 8 ve Çizelge 9'da ifade edilmiştir.

ISO 19036 metodu ile EuroLab Teknik Prosedürü değerleri karşılaştırıldığında analiz sonuçlarına göre 1 .analist ile 2 . analist, 1 . analist ile 3. analist, 1. analist ile 4. analist, 2. analist ile 3. analist, 2. analist ile 4 . analist ve 3 . analist ile 4 . analist arasında istatistiksel olarak anlamlı bir fark bulunmaktadır $(P<0.01)$ ve EuroLab Teknik Prosedürü değerleri daha yüksek çıkmıştır $(P$ $<0.05)$ (Çizelge 2).

Çizelge 2. ISO 19036 metodu ile EuroLab teknik prosedür ölçümlerinin karşılaştırılması Table 2. Comparison of EuroLab technical procedure and ISO 19036 method

\begin{tabular}{|c|c|c|c|c|}
\hline & $\begin{array}{l}\text { U değerleri } \\
\text { Ortalaması }\end{array}$ & U değerleri ss & $\mathrm{t}$ & $P$ \\
\hline ISO 19036 Standard $1(1-2)$ & 0.102645 & 0.0421861 & \multirow{2}{*}{-8.119} & \multirow{2}{*}{$0.000^{*}$} \\
\hline EuroLab Teknik Prosedürü (1-2) & 0.246673 & 0.1347559 & & \\
\hline ISO 19036 Standard1 (1-3) & 0.160073 & 0.0782535 & \multirow{2}{*}{-8.453} & \multirow{2}{*}{$0.000^{*}$} \\
\hline EuroLab Teknik Prosedürü (1-3) & 0.325024 & 0.1421011 & & \\
\hline ISO 19036 Standard1 (1-4) & 0.136485 & 0.0919991 & \multirow{2}{*}{-7.083} & \multirow{2}{*}{$0.000^{*}$} \\
\hline EuroLab Teknik Prosedürü (1-4) & 0.305074 & 0.1635145 & & \\
\hline ISO 19036 Standard1 (2-3) & 0.124502 & 0.0836366 & \multirow{2}{*}{-6.942} & \multirow{2}{*}{$0.000^{*}$} \\
\hline EuroLab Teknik Prosedürü (2-3) & 0.265663 & 0.1404392 & & \\
\hline ISO 19036 Standard $1(2-4)$ & 0.137362 & 0.0807755 & \multirow{2}{*}{-8.220} & \multirow{2}{*}{$0.000^{*}$} \\
\hline EuroLab Teknik Prosedürü (2-4) & 0.302410 & 0.1496958 & & \\
\hline ISO 19036 Standard 1 (3-4) & 0.093406 & 0.0229582 & \multirow[b]{2}{*}{-9.631} & \multirow[b]{2}{*}{$0.000^{*}$} \\
\hline EuroLab Teknik Prosedürü (3-4) & 0.234399 & 0.0989758 & & \\
\hline $\begin{array}{l}* P<0.05 \text { (Global Yaklaşım değerleri } \\
\text { olduğu ortaya çımışıtır) } \\
\text { ss: Kendall's tau_b Katsayısı ve Spearn } \\
\text { t: T testini tanımlamaktadır. } \\
\text { P: P değeri istatistiksel anlamlılığı ifade } \\
\text { U değeri: Ölçüm belirsizliğini tanımlan }\end{array}$ & $\begin{array}{l}19036 \text { değerle } \\
\text { to katsayısı ile } \\
\text { tedir. }\end{array}$ & $\begin{array}{l}\text { inda anlamlı bi } \\
\text { lama }\end{array}$ & & \\
\hline
\end{tabular}


Çizelge 3. NMKL No.8 - ISO 19036 - EuroLab teknik prosedürü karşılaştırması Table 3. Comparison of NMKL No.8 - ISO 19036 - Eurolab technical procedure

\begin{tabular}{|c|c|c|c|c|}
\hline & & $\begin{array}{l}\text { Yemek } \\
\text { (B. cereus) }\end{array}$ & $\begin{array}{l}\text { Peynir } \\
\text { (E. coli) }\end{array}$ & $\begin{array}{c}\text { Süt } \\
\text { (Toplam Mezofilik Aerobik Koloni.) }\end{array}$ \\
\hline \multirow{2}{*}{ NMKL (1-2) } & $\mathrm{U}$ & 2.9831 & 2.8559 & 2.8594 \\
\hline & SR & 1.4915 & 1.4279 & 1.4297 \\
\hline \multirow{2}{*}{ NMKL (1-3) } & $\mathrm{U}$ & 3.0099 & 2.8613 & 2.8398 \\
\hline & SR & 1.5050 & 1.4306 & 1.4199 \\
\hline \multirow{2}{*}{ NMKL (1-4) } & $\mathrm{U}$ & 2.9876 & 2.9012 & 2.7865 \\
\hline & SR & 1.4938 & 1.4506 & 1.3933 \\
\hline \multirow{2}{*}{ NMKL (2-3) } & $\mathrm{U}$ & 3.0000 & 2.7815 & 2.8616 \\
\hline & SR & 1.5000 & 1.3908 & 1.4308 \\
\hline \multirow{2}{*}{ NMKL (2-4) } & $\mathrm{U}$ & 2.9776 & 2.8226 & 2.8087 \\
\hline & SR & 1.4888 & 1.4113 & 1.4043 \\
\hline \multirow{2}{*}{ NMKL (3-4) } & $\mathrm{U}$ & 3.0045 & 2.8280 & 2.7914 \\
\hline & SR & 1.5022 & 1.4140 & 1.3957 \\
\hline \multirow{2}{*}{ ISO 19036 (1-2) } & $\mathrm{U}$ & 0.1353 & 0.1145 & 0.0581 \\
\hline & SR & 0.0677 & 0.0573 & 0.0290 \\
\hline \multirow{2}{*}{ ISO 19036 (1-3) } & $\mathrm{U}$ & 0.1232 & 0.2100 & 0.1471 \\
\hline & SR & 0.0616 & 0.1050 & 0.0735 \\
\hline \multirow{2}{*}{ ISO 19036 (1-4) } & $\mathrm{U}$ & 0.0819 & 0.2046 & 0.1229 \\
\hline & SR & 0.0410 & 0.1023 & 0.0614 \\
\hline \multirow{2}{*}{ ISO 19036 (2-3) } & $\mathrm{U}$ & 0.0768 & 0.1867 & 0.1100 \\
\hline & SR & 0.0384 & 0.0934 & 0.0550 \\
\hline \multirow{2}{*}{ ISO $19036(2-4)$} & $\mathrm{U}$ & 0.0893 & 0.1936 & 0.1292 \\
\hline & SR & 0.0446 & 0.0968 & 0.0646 \\
\hline \multirow{2}{*}{ ISO 19036 (3-4) } & $\mathrm{U}$ & 0.0998 & 0.1067 & 0.0737 \\
\hline & SR & 0.0499 & 0.0534 & 0.0368 \\
\hline \multirow{2}{*}{$\begin{array}{l}\text { EuroLab Teknik } \\
\text { Prosedürü }(1-2)\end{array}$} & $\mathrm{U}$ & 0.3852 & 0.2703 & 0.0846 \\
\hline & $\begin{array}{l}\mathrm{SR} \\
\end{array}$ & 0.1926 & 0.1351 & 0.0423 \\
\hline \multirow{2}{*}{$\begin{array}{l}\text { EuroLab Teknik } \\
\text { Prosedürü (1-3) }\end{array}$} & $\mathrm{U}$ & 0.3267 & 0.4559 & 0.1926 \\
\hline & $\begin{array}{l}\text { SR } \\
\end{array}$ & 0.1633 & 0.2279 & 0.0963 \\
\hline \multirow{2}{*}{$\begin{array}{l}\text { EuroLab } \quad \text { Teknik } \\
\text { Prosedürü }(1-4)\end{array}$} & $\mathrm{U}$ & 0.2990 & 0.4671 & 0.1491 \\
\hline & $\begin{array}{l}\text { SR } \\
\end{array}$ & 0.1495 & 0.2336 & 0.0745 \\
\hline \multirow{2}{*}{$\begin{array}{l}\text { EuroLab Teknik } \\
\text { Prosedürü }(2-3)\end{array}$} & $\mathrm{U}$ & 0.2627 & 0.4041 & 0.1302 \\
\hline & $\begin{array}{l}\text { SR } \\
\end{array}$ & 0.1313 & 0.2021 & 0.0651 \\
\hline \multirow{2}{*}{$\begin{array}{l}\text { EuroLab } \quad \text { Teknik } \\
\text { Prosedürü }(2-4)\end{array}$} & $\mathrm{U}$ & 0.2679 & 0.4543 & 0.1850 \\
\hline & $\begin{array}{l}\text { SR } \\
\end{array}$ & 0.1339 & 0.2272 & 0.0925 \\
\hline \multirow{2}{*}{$\begin{array}{l}\text { EuroLab Teknik } \\
\text { Prosedürü (3-4) }\end{array}$} & $\mathrm{U}$ & 0.2822 & 0.3064 & 0.1146 \\
\hline & $\begin{array}{l}\text { SR } \\
\end{array}$ & 0.1411 & 0.1532 & 0.0573 \\
\hline
\end{tabular}

$\mathrm{S}_{\mathrm{R}: \text { Tekrarüretilebilirlik Standart Sapmas1 }}$

U: Ölçüm Belirsizliği

$S_{R}$ değeri 0'a yaklaştıkça değişim daha az olduğu için tutarlllık daha yüksektir. Buna göre

$\mathrm{U}$ değeri $0^{\prime}$ a yakın olan sonuçlarda daha az sapma vardır. 


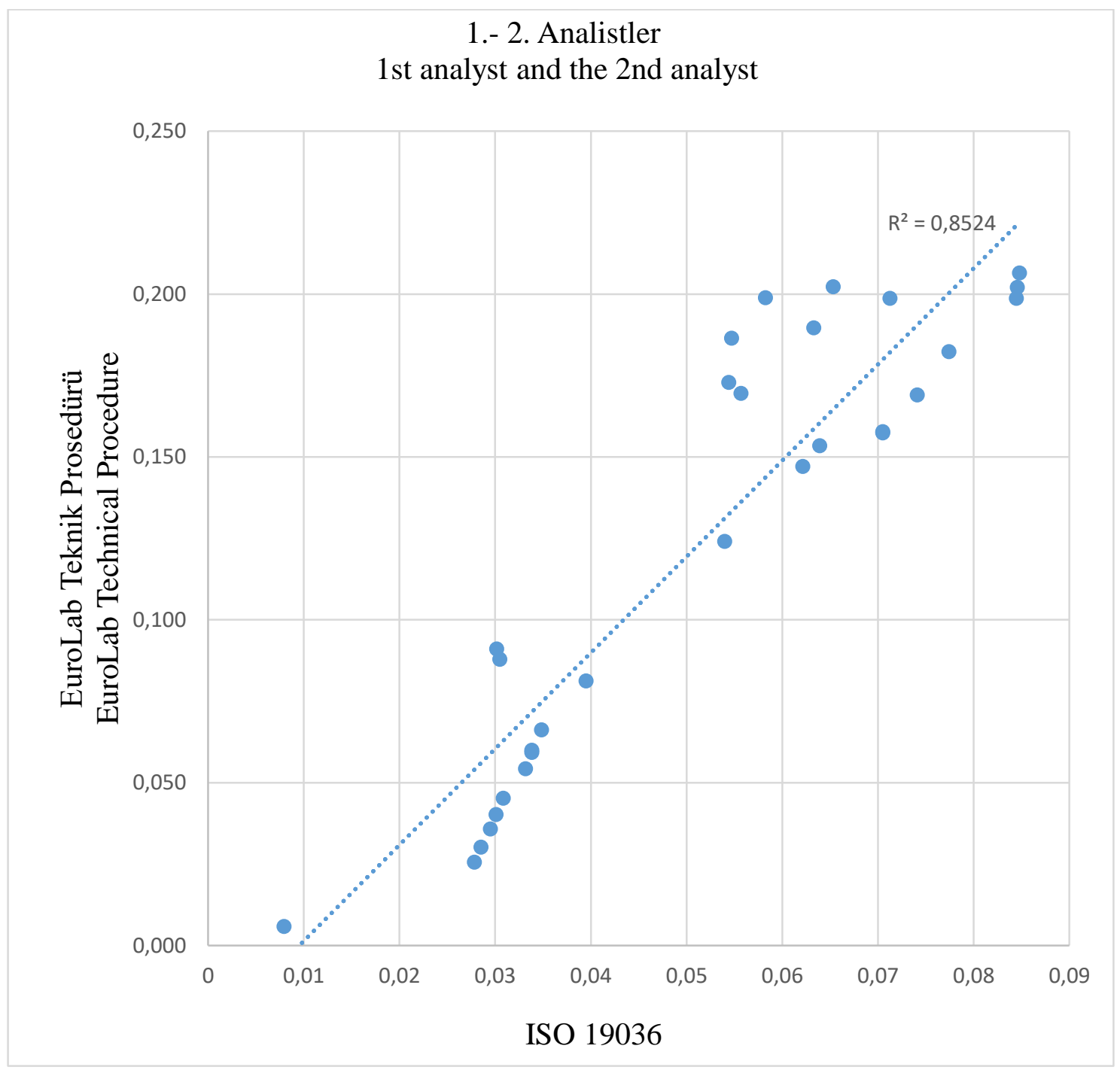

*R: Regresyon katsayis1

Şekil 1. 1. analist ile 2. analistin ISO 19036 ile hesaplanan $S_{R}$ değerleri ile EuroLab teknik prosedürü formülü kullanılarak hesaplanan SR değerleri arasındaki ilişki grafiği

*R: Regression coefficient

Figure 1. Graph showing relationship between $S_{R}$ values of the $1^{\text {st }}$ analyst and the $2^{\text {nd }}$ analyst calculated using ISO 19036 value and EuroLab technical Procedure $S_{R}$ values calculated using formula 


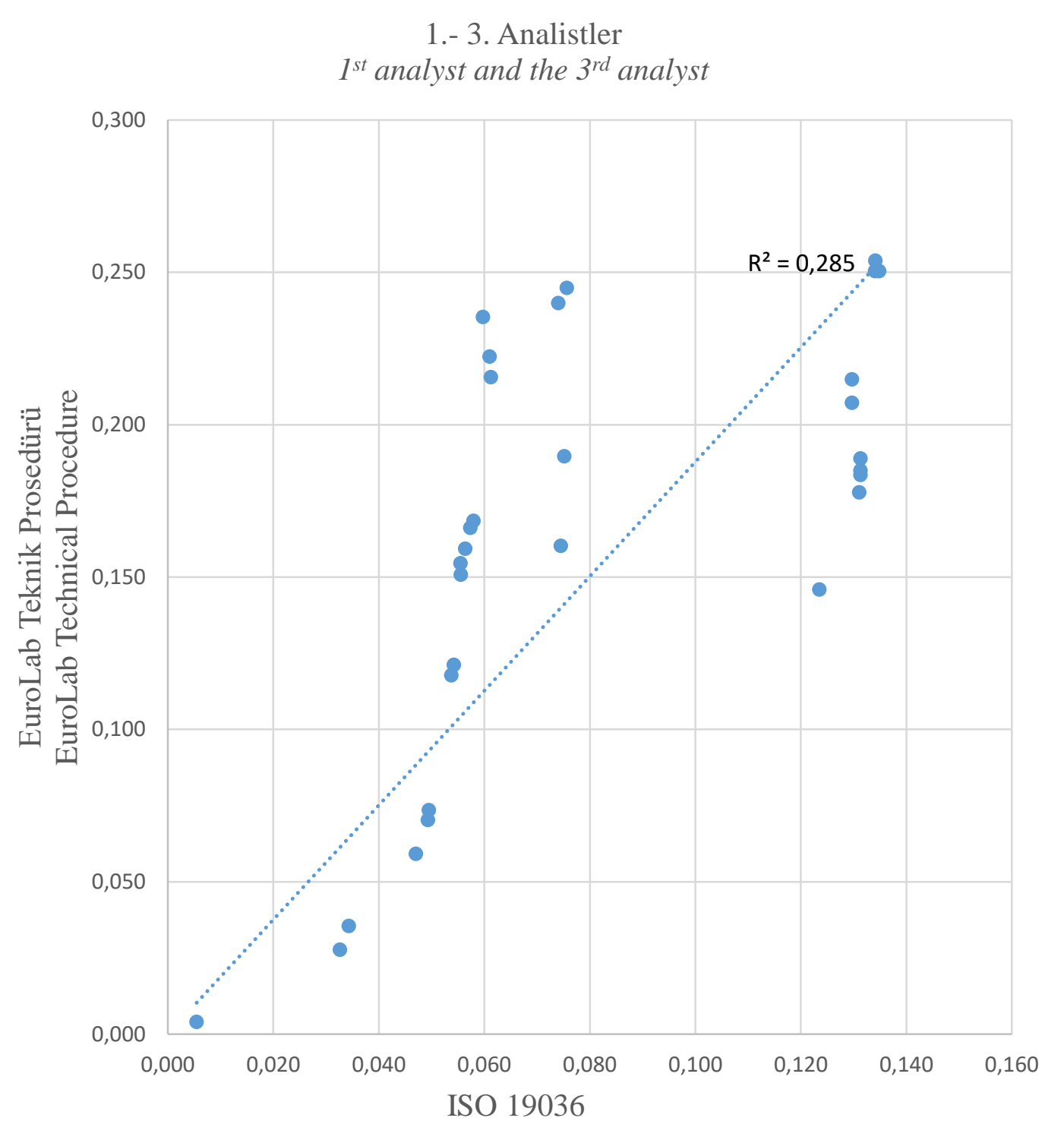

Şekil 2. 1. analist ile 3. analistin ISO 19036 ile hesaplanan $S_{R}$ değerleri ile EuroLab teknik prosedürü kullanılarak hesaplanan $S_{R}$ değerleri arasındaki ilişki grafiği

Figure 2. Graph showing relationship between $S_{R}$ values of the $1^{\text {st }}$ analyst and the $3^{\text {rd }}$ analyst calculated using ISO 19036 value and $S_{R}$ values calculated using EuroLab technical procedure formula 


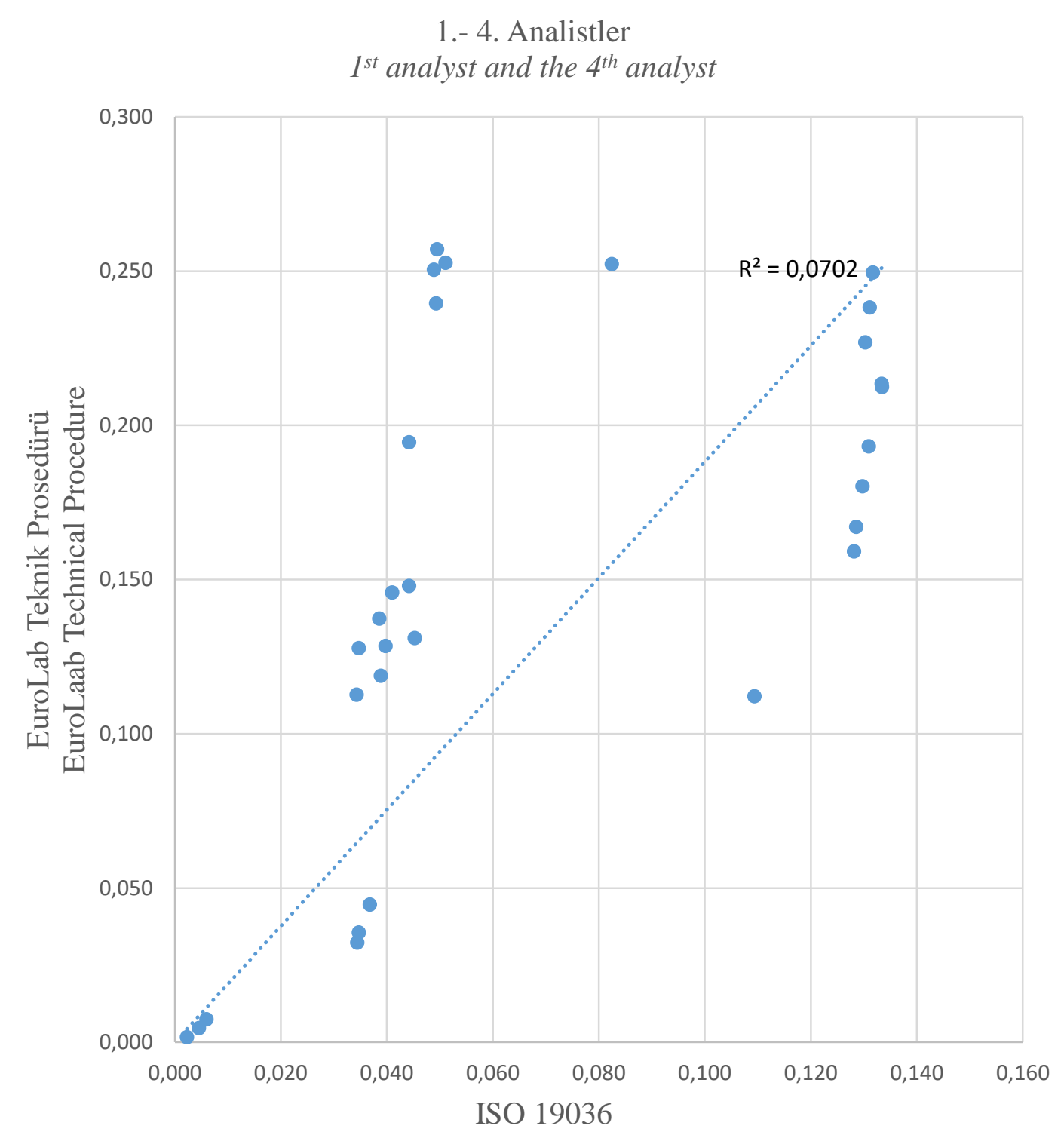

Şekil 3. 1. analist ile 4. analistin ISO 19036 ile hesaplanan $S_{R}$ değerleri ile EuroLab teknik prosedürü kullanılarak hesaplanan $S_{R}$ değerleri arasındaki ilişki grafiği

Figure 3. Graph showing relationship between $S_{R}$ values of the $1^{\text {st }}$ analyst and the $4^{\text {th }}$ analyst calculated using ISO 19036 value and $S_{R}$ values calculated using EuroLab technical procedure formula 


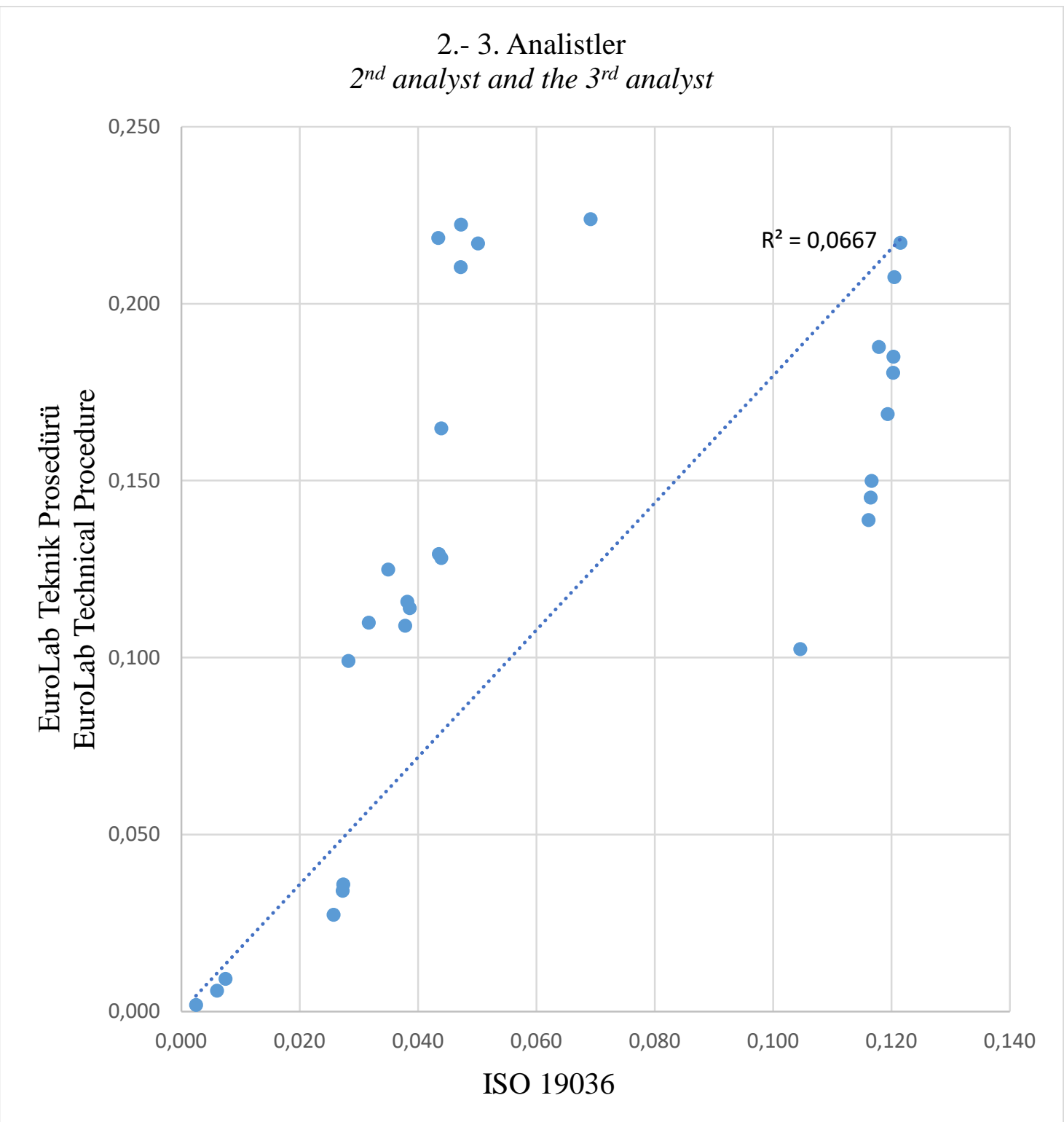

Şekil 4. 2. analist ile 3. analistin ISO 19036 ile hesaplanan $\mathrm{S}_{\mathrm{R}}$ değerleri ile EuroLab teknik prosedürü kullanılarak hesaplanan SR değerleri arasındaki ilişki grafiği

Figure 4. Graph showing relationship between $S_{R}$ values of the $2^{\text {nd }}$ analyst and the $3^{\text {rd }}$ analyst calculated using ISO 19036 value and $S_{R}$ values calculated using EuroLab technical procedure formula 


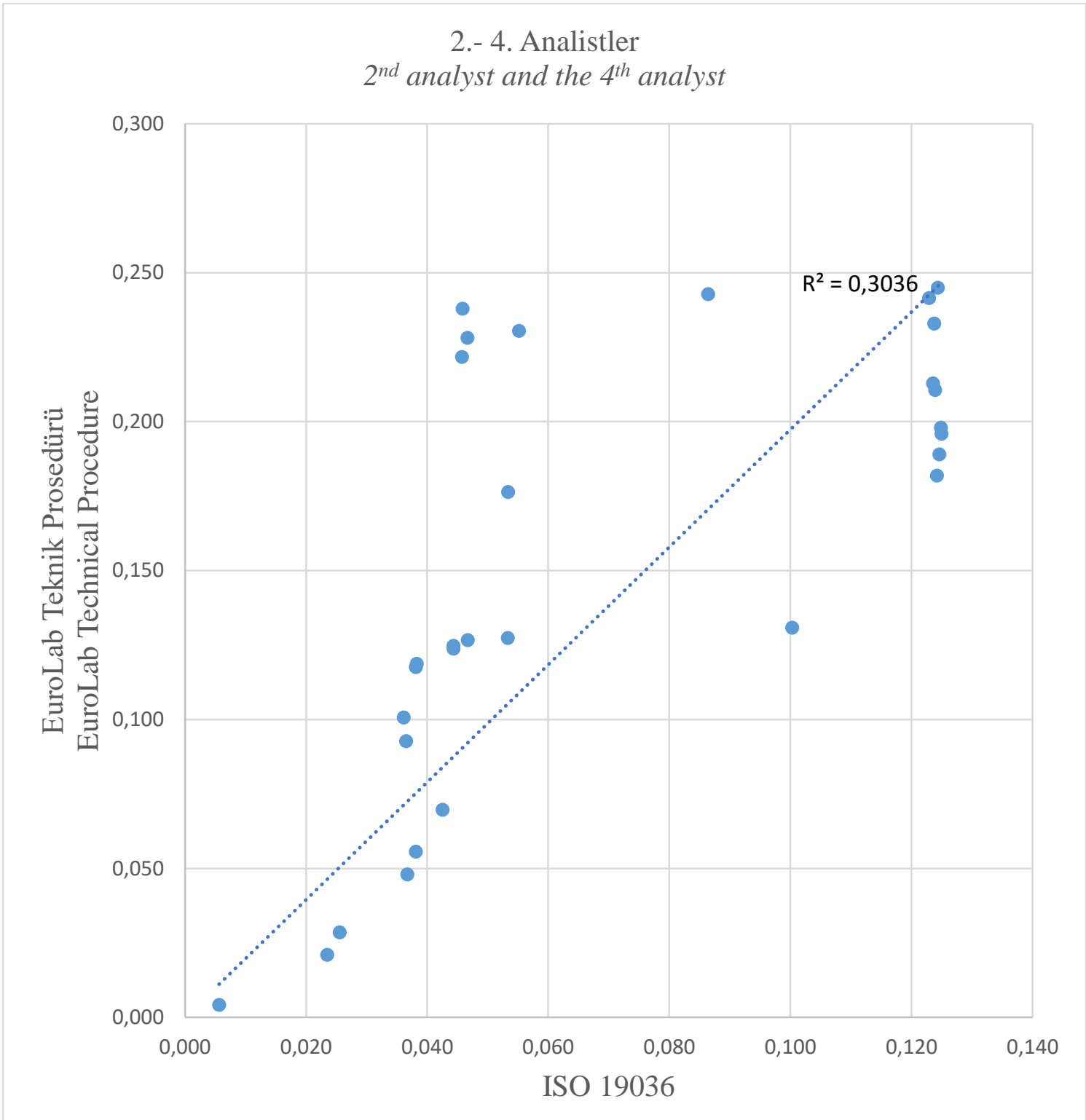

Şekil 5. 2. analist ile 4. analistin ISO 19036 ile hesaplanan $S_{R}$ değerleri ile EuroLab teknik prosedürü kullanılarak hesaplanan SR değerleri arasındaki ilişki grafiği

Figure 5. Graph showing relationship between $S_{R}$ values of the $2^{\text {nd }}$ analyst and the $4^{\text {th }}$ analyst calculated using ISO 19036 value and $S_{R}$ values calculated using EuroLab technical procedure formula 


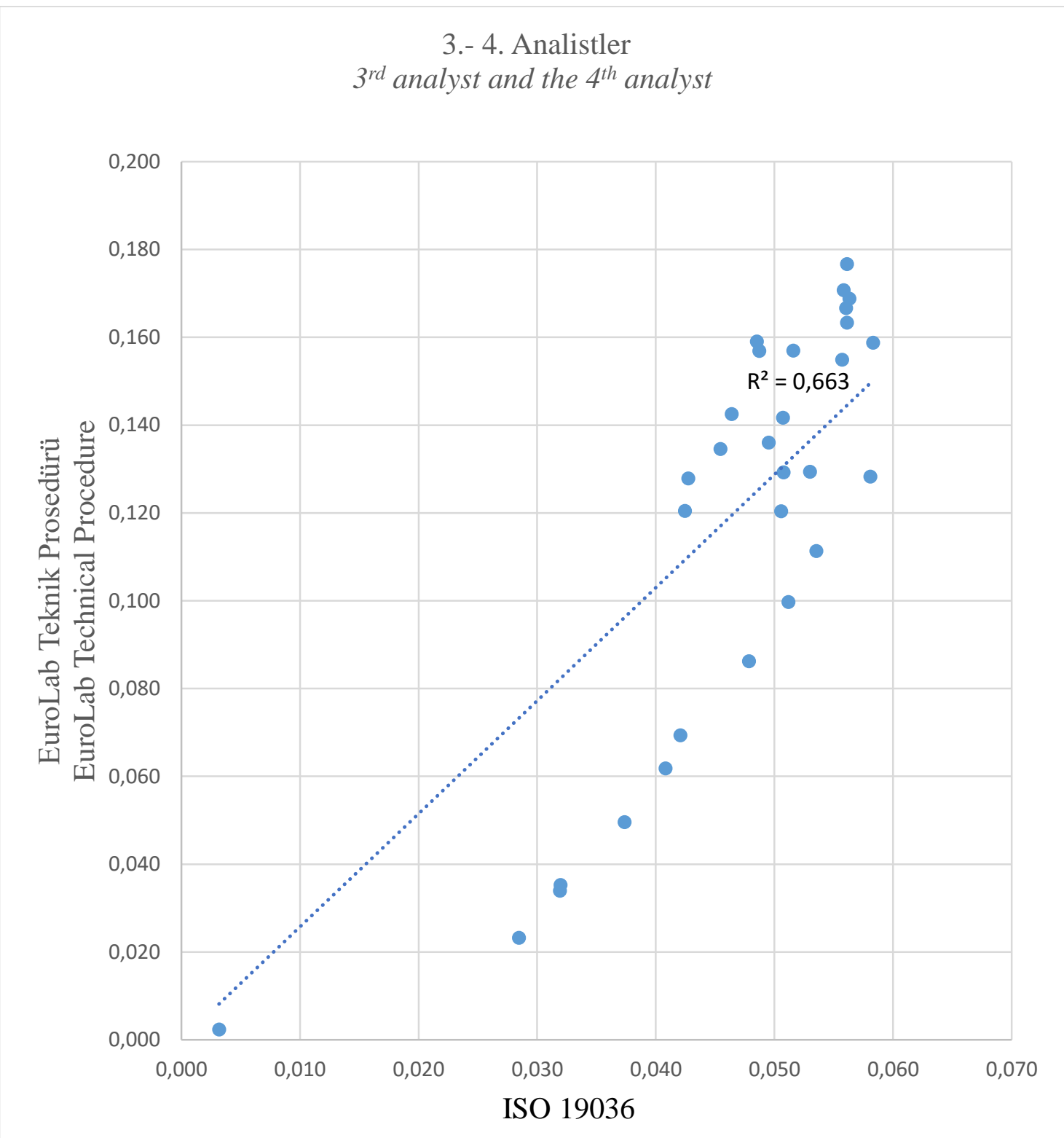

Şekil 6. 3. analist ile 4. analistin ISO 19036 ile hesaplanan $S_{R}$ değerleri ile EuroLab teknik prosedürü kullanılarak hesaplanan SR değerleri arasındaki ilişki grafiği

Figure 6. Graph showing relationship between $S_{R}$ values of the $3^{\text {rd }}$ analyst and the $4^{\text {th }}$ analyst calculated using ISO 19036 value and $S_{R}$ values calculated using EuroLab technical procedure formula 


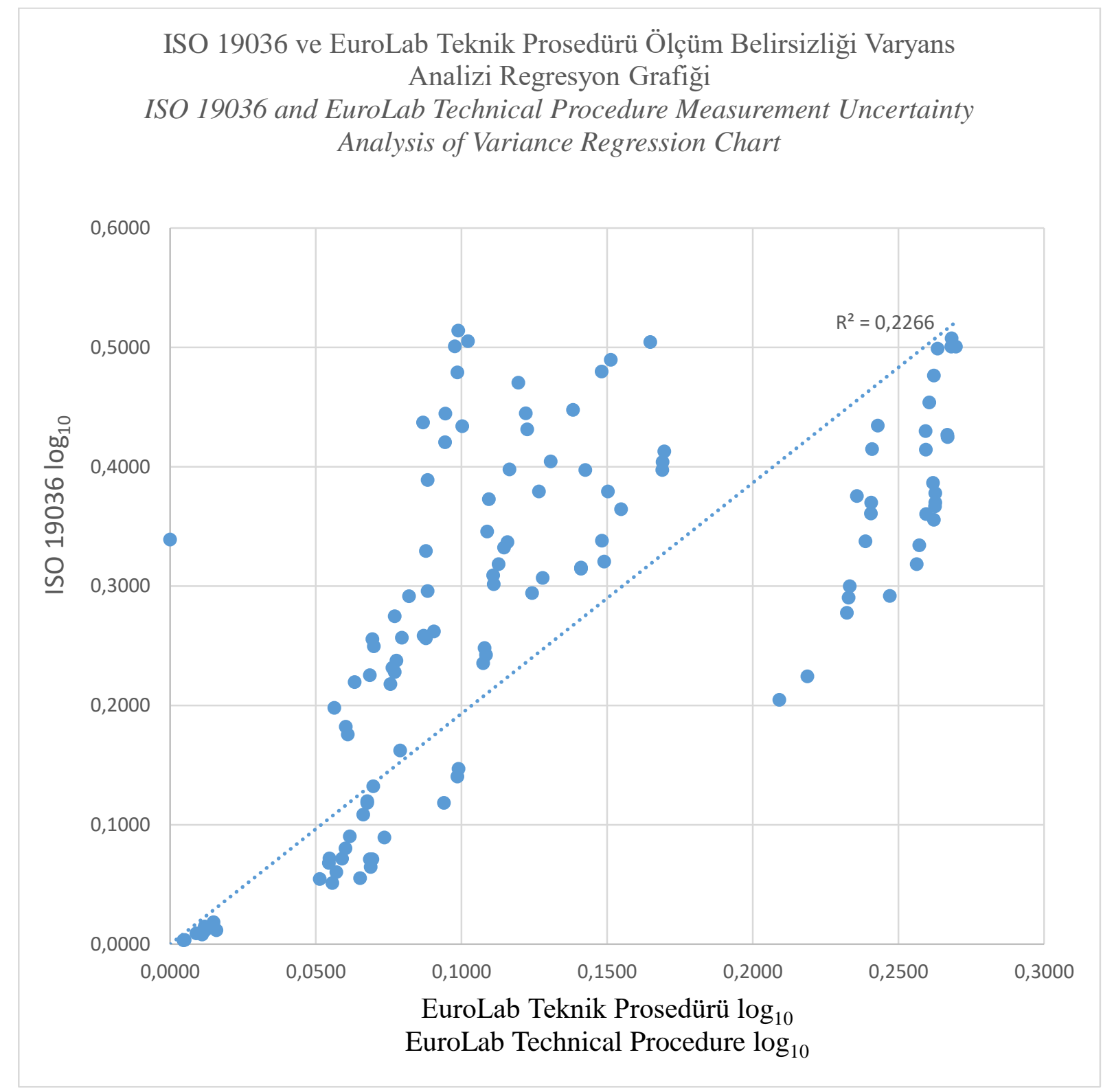

Şekil 7. Tüm verilerin ISO 19036 ile hesaplanan $S_{R}$ değerleri ile EuroLab teknik prosedürü ile hesaplanan SR değerleri arasındaki ilişki grafiği

Figure 7. Graph showing relationship between $S_{R}$ values of all data calculated using ISO 19036 and $S_{R}$ values calculated with EuroLab technical procedure 
Çizelge 4. 1. ve 2. analistlerin ISO 19036, EuroLab teknik prosedürü ve NMKL No.8’e ait ölçüm belirsizliği karşılaştırmaları

Table 4. Comparison of measurement uncertainty of $1^{\text {st }}$ analyst and the $2^{\text {nd }}$ analyst about of the ISO 19036, EuroLab technical procedure, and NMKL No.8

\begin{tabular}{|lccc|}
\hline & $\begin{array}{c}\text { Yemek } \\
\text { (B. cereus) }\end{array}$ & $\begin{array}{c}\text { Peynir } \\
\text { (E. coli) }\end{array}$ & $\begin{array}{c}\text { Süt } \\
\text { (Toplam Mezofilik Aerobik } \\
\text { Koloni) }\end{array}$ \\
\hline NMKL (1-2) & 2.98 & 2.85 & 2.85 \\
ISO 19036 (1-2) & 0.13 & 0.11 & 0.05 \\
EuroLab Teknik Prosedür (1-2) & 0.38 & 0.27 & 0.08 \\
\hline
\end{tabular}

Çizelge 5. 1. ve 3. analistlerin ISO 19036, EuroLab teknik prosedürü ve NMKL No.8’e ait ölçüm belirsizliği karşılaştırmaları

Table 5. Comparison of measurement uncertainty of $1^{\text {st }}$ analyst and the $3^{\text {rd }}$ analyst about of the ISO 19036, EuroLab technical procedure, and NMKL No.8

\begin{tabular}{|lccc|}
\hline & $\begin{array}{c}\text { Yemek } \\
\text { (B. cereus) }\end{array}$ & $\begin{array}{c}\text { Peynir } \\
\text { (E. coli) }\end{array}$ & $\begin{array}{c}\text { Süt } \\
\text { (Toplam Mezofilik Aerobik Koloni) }\end{array}$ \\
\hline NMKL (1-3) & 3.00 & 2.86 & 2.83 \\
ISO 19036 (1-3) & 0.12 & 0.21 & 0.14 \\
EuroLab Teknik Prosedür (1-3) & 0.32 & 0.45 & 0.19 \\
\hline
\end{tabular}

Çizelge 6. 1. ve 4. analistlerin ISO 19036, EuroLab teknik prosedürü ve NMKL No.8’e ait ölçüm belirsizliği karşılaştırmaları

Table 6. Comparison of measurement uncertainty of $1^{\text {st }}$ analyst and the $4^{\text {th }}$ analyst about of the ISO 19036, EuroLab technical procedure, and NMKL No.8

\begin{tabular}{|lccc|}
\hline & $\begin{array}{c}\text { Yemek } \\
\text { (B. cereus) }\end{array}$ & $\begin{array}{c}\text { Peynir } \\
\text { (E. coli) }\end{array}$ & $\begin{array}{c}\text { Süt } \\
\text { (Toplam Mezofilik Aerobik Koloni) }\end{array}$ \\
\hline NMKL (1-4) & 2.98 & 2.90 & 2.78 \\
ISO 19036 (1-4) & 0.08 & 0.20 & 0.12 \\
EuroLab Teknik Prosedür (1-4) & 0.29 & 0.46 & 0.14 \\
\hline
\end{tabular}

Çizelge 7. 2. ve 3. analistlerin ISO 19036, EuroLab teknik prosedürü ve NMKL No.8'e ait ölçüm belirsizliği karş̧laştırmaları

Table 7. Comparison of measurement uncertainty of $2^{\text {nd }}$ analyst and the $3^{\text {rd }}$ analyst about of the ISO 19036, EuroLab technical procedure, and NMKL No.8

\begin{tabular}{|lccc|}
\hline & $\begin{array}{c}\text { Yemek } \\
\text { (B. cereus) }\end{array}$ & $\begin{array}{c}\text { Peynir } \\
\text { (E. coli) }\end{array}$ & $\begin{array}{c}\text { Süt } \\
\text { (Toplam Mezofilik Aerobik } \\
\text { Koloni) }\end{array}$ \\
\hline NMKL (2-3) & 3.00 & 2.78 & 2.86 \\
ISO 19036 (2-3) & 0.07 & 0.18 & 0.11 \\
EuroLab Teknik Prosedür (2-3) & 0.26 & 0.40 & 0.13 \\
\hline
\end{tabular}


Çizelge 8. 2. ve 4. analistlerin ISO 19036, EuroLab teknik prosedürü ve NMKL No.8’e ait ölçüm belirsizliği karşılaştırmaları

Table 8. Comparison of Measurement Uncertainty of $2^{\text {nd }}$ analyst and the $4^{\text {th }}$ analyst about of the ISO 19036, EuroLab technical procedure, and NMKL No.8

\begin{tabular}{|lccc|}
\hline & $\begin{array}{c}\text { Yemek } \\
(\text { B. cereus })\end{array}$ & $\begin{array}{c}\text { Peynir } \\
(\text { E. coli) }\end{array}$ & $\begin{array}{c}\text { Süt } \\
\text { (Toplam Mezofilik Aerobik } \\
\text { Koloni) }\end{array}$ \\
\hline NMKL (2-4) & 2.97 & 2.82 & 2.80 \\
ISO 19036 (2-4) & 0.08 & 0.19 & 0.12 \\
EuroLab Teknik Prosedür (2-4) & 0.26 & 0.45 & 0.18 \\
\hline
\end{tabular}

Çizelge 9. 3. ve 4. analistlerin ISO 19036, EuroLab teknik prosedürü ve NMKL No.8’e ait ölçüm belirsizliği karşılaştırmaları

Table 9. Comparison of measurement uncertainty of $3^{\text {rd }}$ analyst and the $4^{\text {th }}$ analyst about of the ISO 19036, EuroLab technical procedure, and NMKL No.8

\begin{tabular}{|lccc|}
\hline & $\begin{array}{c}\text { Yemek } \\
\text { (B. cereus) }\end{array}$ & $\begin{array}{c}\text { Peynir } \\
(\text { E. coli) }\end{array}$ & $\begin{array}{c}\text { Süt } \\
\text { (Toplam Mezofilik Aerobik Koloni) }\end{array}$ \\
\hline NMKL (3-4) & 3.00 & 2.82 & 2.79 \\
ISO 19036 (3-4) & 0.09 & 0.10 & 0.07 \\
EuroLab Teknik Prosedür (3-4) & 0.28 & 0.30 & 0.11 \\
\hline
\end{tabular}

Tüm veriler varyans analizi ile değerlendirildiğinde ise (Şekil 7) ISO 19036 ve EuroLab Teknik Prosedürü düşüncesi ile gerçekleştirilen ölçüm belirsizliği hesaplamaları için bağıl standart sapma kullanılmaktadır. Bu nedenle, belirsizlik sonuçları çalışmayı da destekler şekilde oldukça düşük olarak elde edilmiştir. Ancak, NMKL No.8'de tüm verilerin ortalamaları bir potada hesaplanmakta ve doğal olarak tıpk1 bu çalışmada olduğu gibi ölçüm belirsizliği sonuçları yüksek olarak elde edilmektedir. Araştırma sonuçlarına göre NMKL No. 8 metodunda tüm matriks ve analizlerde birbirine oldukça yakın ancak diğer metotlara kıyasla daha yüksek ölçüm belirsizliği elde edilmiş; süt matriksi (heterojen özelliği nedeniyle) ile çalışlan toplam mezofilik aerobik mikroorganizma sayısının EuroLab Teknik Prosedüründe ise en düşük ölçüm belirsizliğine sahip olduğu ortaya konulmuştur.

ISO 19036 standardına göre petrilerde 10 koloni ve aşağı saylda mikroorganizma metot için başarılı sonuçlar vermemekte (ISO, 2019; Yllmaz vd.,
2019; ISO, 2021), bu durumlarda EuroLab teknik prosedürü ile hesaplama tekniği araştırmacı tarafindan önerilmektedir (Torlak, 2012).

Araştırmaya benzer şekilde, Torlak (2012) peynirde Staphylococcus aureus üzerine yaptığ1 çalışmalarında ISO 19036 ile ölçüm belirsizliği sonucunu U $\left(\log _{10}\right)=0.23$ olarak EuroLab teknik prosedürüne göre belirsizliği ise $\mathrm{U}=\% 600$ olarak ortaya koymuştur. Araştırmacı, \%45-75 aralıkta ölçüm belirsizliği verilerinde EuroLab teknik prosedürünün sonuçları log'a çevirmeden rahatlıkla kullanılabileceğini, limit değer olan $\% 75$ ve üzerindeki belirsizlik durumlarında ise ISO yaklaşımının kullanımının gerekliliğini belirtmiştir.

Blasi vd. (2013), yaptıkları validasyon ve ölçüm belirsizliği çalışmalarında ISO 19036 metodu ile yukardan aşağıya (Top down) tüme varım yöntemi olan global yaklaşımın başarılı olduğunu ortaya koymuşlardır.

Jarvis (2015), mikrobiyologların mikrobiyolojik analizlerde ölçüm belirsizliği çalışmaları için 
genellikle sonuçların $\log _{10}$ 'a çevirerek kullandıklarını, koloni sayısı $<100 \mathrm{kob} /$ g'dan daha düşük olan analiz sonuçlarında belirsizlik hesab1 için poisson dağıllımı gerçekleştirildiğini belirtmiştir. Norli (2017), yaptığı çalışmada ISO 19036 ile NMKL metotlarına ait ölçüm belirsizliklerinin aynı olduğunu bildirmiştir.

Tipk1 araştırmada olduğu gibi Yılmaz vd. (2019), NMKL prosedürünün ISO/TS 19036'ya göre yapılan hesaplamaların bünyesinde sunduğu metoda göre tüm değişkenlerin değerlendirmeye katılmaması nedeniyle daha düşük sonuçlar alındığını belirttiğini; ancak karşılaştırma sonuçlarında ara kesinliğin ortaya konulmasında gerçekte tüm alanlarda karşılaşılabilecek değişikliklerin analize yansıdığının görülmesinin öneminin olduğunu ve uygulamanın ISO/TS 19036'nın A ve B koşulları ve diğer tüm değissiklik uygulamaları ile sağlandiğını, tüm bu değişikliklerin NMKL prosedür uygulamasina yansitıldığında ise prosedürde belirtilen değerlendirmenin oluşmasının beklenilmemesi gerektiğini belirtmişlerdir.

\section{SONUÇ}

Mikrobiyolojik analizlerin raporlanmasında ölçüm belirsizliği hesaplamaları büyük oranda kullanılmamakla beraber numune sonuçlarının uygunsuzluğu durumunda müşterinin istekleri doğrultusunda analiz raporlarında belirtilmek durumunda kullanilabilir.

NMKL yaklaşımında çoğunlukla tekrarlanabilirlik çalışmasından gelen değişkenlik de hesaplamaya katılmaktadır. $\mathrm{Bu}$ nedenle ISO yaklaşımından daha yüksek bir standart sapma elde edilmesi olasidır (Yılmaz vd., 2019). Bununla birlikte ISO yaklaşımı ve EuroLab Teknik Prosedürü, aynı gıda grubu içinde değişik numunelerde çalışmayı sağlamaya ve tekrarüretilebilirlik koşullarında iki paralel olarak çalışılması halinde daha hassas sonuçlar vermeye elverişli metotlardır.

Düşük mikroorganizma yükü var ise bileşen yani ISO 19036 yaklaşımı daha doğrudur. Çalışlan örneklerde hetorojenlik fazla ise ISO 19036 metodundan sonra tercih edilecek en yakin yaklaşım EuroLab Teknik Prosedürüdür. Eğer, ortam koşullarının, donanım, matriks vb. tüm değiştirilebilecek unsurların değiştirilerek analizlerin gerçekleştirilmesi ve bir ölçüm belirsizliği ortaya konulmak isteniyorsa ISO 19036 standard1 tercih edilmelidir. Gerçekleştirilen çalışma ile istatistiki olarak ISO 19036 metodu ile karşılaştırılan sonuçların EuroLab Teknik Prosedürüne göre, ISO 19036 ve EuroLab Teknik Prosedürünün ise NMKL No.8 standardına göre daha hassas aralıkta ölçüm belirsizliği sonucu ortaya koyduğu belirlenmiştir.

\section{ÇIKAR ÇATIŞMASI BEYANI}

Yazar çıkar çatışması olmadığını beyan etmektedir.

\section{TEŞEKKÜR}

Çalışmada görüşlerini esirgemeyen Prof. Dr. Emrah Torlak ile Dr. Erdem Danyer'e teşekkür ederim.

\section{KAYNAKLAR}

Blasi, G., Petruzzelli, A., Ottaviani, D., Fisichella, S., Raimo, E.D., Valiani, A., Capuccella, M., Scuota, S., Haouet, M. N. (2013). Assessment of reproducibility and uncertainty of food microbiology methods: statistical approach of a multi-site Laboratory. Accred Qual Assur, 18, 143 148.

Corry, J. E. L., Jarvis, B., Passmore, S., Hedges, A. (2007). A critical review of measurement uncertainty in the enumeration of food microorganisms. Food Microbiol, 24, 230-253.

Dereani, V. R., Sarić, M. M. (2010). Validation and measurement uncertainty estimation in food microbiology: differences between quantitative and qualitative methods. Validation and Measurement in Food Microbiol, 60 (3): 207-213.

EuroLab Technical Report No.1 (2007). Measurement uncertainty revisited: alternative approaches to uncertainty test results and the uncertainty of evaluation. https://eurolabd.de/files/measurement_uncertainty_revisited alternative_approaches_to_uncertainty_evaluatio n.pdf

Eurachem Guide (2013). Accreditation for microbiological laboratories.www.eurachem.org/ 
images/stories/Guides/pdf/Eurachem_Guide_ AML_2013.

Forster, L. I. (2003). Measurement uncertainty in microbiology. J AOAC Int, 86 (5): 1089-1094.

Gašljević, V. (2004). Validacija mikrobioloških metoda. Seminar Hrvatskog mjeriteljskog društva, Materijali, 1. izdanje (05/2004).

ISO (2017b). Guidance for the use of repeatibility, reproducibility and trueness estimates in measurement uncertainty evaluation. ISO 21748: 2017

ISO (2019). Microbiology of the food chain Guidelines for the estimations of measurement uncertainty for quantitative determinations. ISO 19036: 2019

ISO (2021). Microbiology of the food chainMethod validation- Part:3. Prtotocol for the verification of reference methods and validated alternative methods in a single laboratory. ISO 16140-3: 2021

Jarvis, B., Hedges, A. J, Corry, J. E. L. (2007). Assessment of measurement uncertainty for quantitative methods of analysis: Comparative assessment of the precision (uncertainty) of bacterial colony counts. Int J Food Microbiol, 116, 44-51.

Jarvis, B. (2015). Statistical aspects of the microbiological examination of foods. Chapter 11. Estimation of measurement uncertainity. $3^{\text {rd }}$ edition. ISBN:978-0-12-803973-1.

JCGM 200 (2012). International Vocabulary of Metrology. Basic and general concepts and associated terms. $3^{\text {td }}$ edition. VIM, 2008.

Lombard, B. (2006). Estimation of measurement uncertainty in food microbiology: The ISO approach. Accred Qual Assur, 17, 94-100.
NordVal International (NMKL) Procedure No. 8 (2004). Measurement of uncertainty in quantitative microbiological examination of foods. $4^{\text {th }}$ Edition.

NordVal International (NMKL) Procedure No. 32 (2017). Verification of microbiological methods.

Norli, H. S. (2017). Measurement Uncertainty in Microbiological Examination of Foods. Eurachem $-A O A C$ Europe Workshop. Norwegian Veterinary Institute.

Torlak, E. (2012). Alternative calculation of measurement uncertainty with global approach in food microbiology. Accred Qual Assur, 17, 597601.

TS EN ISO (2017a). Deney ve Kalibrasyon Laboratuvarlarının Yeterliliği İçin Genel Şartlar (18. 12. 2017). TS EN ISO/IEC 17025: 2017

TS/ ISO (2000). Ölçme Metotlarının ve Sonuçlarının Doğruluğu (Gerçeklik ve Kesinlik)Bölüm 3: Standard Bir Ölçme Metodunun Kesinliğinin Ara Ölçmeleri (Kasım, 2000). TS 5822-3 ISO 5725-3: 2000

TÜRKAK (2015). Deney/analiz sonuçlardaki ölçüm belirsizliği tahmini için TÜRKAK prensipleri. Türk Akreditasyon Kurumu Rehberi (09.07.2015).

TÜRKAK (2019). Metodun Geçerli Kılınması ve Doğrulanması İçin Bilgilendirme Kılavuzu.

Yılmaz, A., Yıldırım, G., Çakmak Sancar, B., Yolci Ömeroğlu, P. (2019). Mikrobiyolojik Analizlerde Metotların Doğrulanması ve Geçerli Kılınması. Gıda Mikrobiyolojisi, Halkman, A. K. (ed.), Başak Matbaacilık ve Tanıtım Hizmetleri Ltd, Şti, Ankara, Türkiye, s.687, ISBN:978-605-45-683-5. 